\title{
Letters
}

Website: bmj.com

Email: letters@bmj.com

\section{Post-traumatic stress disorder}

\section{Disorder takes away human dignity and character}

EDITOR-Encouraged by Summerfield's revelation about post-traumatic stress disorder, I imagined myself going to my clinic the next day and, at last, telling my patients who have post-traumatic stress disorder that their disorder is but social invention. I also thought that I would apologise, admitting that I was wrong in choosing to diagnose their problem and thereby medicalise their condition instead of seeing it as normal human suffering. Given that suffering is normal, as Summerfield says, I was also prepared to encourage my patients to be happy with having survived adversity and never again mention the word victim. It is a matter of dignity. Better be normal and suffer than have a mental disorder treated.

My daydreaming continued, and I saw myself meeting an anorectic patient, for whom I care very much, and telling her that given the social roots of her disease in ideals of feminine thinness, she should simply start eating. To my very sick schizophrenic patient, overwhelmed by demonic exacerbation, I was to show that schizophrenia is but a scientific delusion. ${ }^{2}$ So far for social constructivism.

\section{Advice to authors \\ We prefer to receive all responses electronically, sent either directly to our website or to the editorial office as email or on a disk. Processing your letter will be delayed unless it arrives in an electronic form. \\ We are now posting all direct submissions to our website within 24 hours of receipt and our intention is to post all other electronic submissions there as well. All responses will be eligible for publication in the paper journal. \\ Responses should be under 400 words and relate to articles published in the preceding month. They should include $\leqslant 5$ references, in the Vancouver style, including one to the BMJ article to which they relate. We welcome illustrations. \\ Please supply each author's current appointment and full address, and a phone or fax number or email address for the corresponding author. We ask authors to declare any competing interest. Please send a stamped addressed envelope if you would like to know whether your letter has been accepted or rejected. \\ Letters will be edited and may be shortened. \\ bmj.com \\ letters@bmj.com}

If anything, the birth of post-traumatic stress disorder exemplifies how good it is that despite orthodoxy and haughtiness the medical profession is sometimes forced to listen to people's pain. Not that post-traumatic stress disorder is built in stone. But neither are depression, psychosis, or delirium. Meanings change with time, and I hope that this will continue. What is, however, fascinating in post-traumatic stress disorder is that, despite its tentative beginnings, this diagnosis has generated more replicable biological findings than many traditional disorders. ${ }^{3}$ Moreover, the development of post-traumatic stress disorder in traumatised people offers a major opportunity to study the ways in which mental events transform the central nervous system. ${ }^{4}$ The marriage between posttraumatic stress disorder and the neurosciences seems more productive than the disorder's acceptance in some circles.

I wish to protest, once again, against the reluctance to identify a mental disorder in those who suffer, just because this might become a psychiatric diagnosis. I thought that those days were over; that human dignity is not lost when one has a mental disorder.

Doctors should encourage their patients to disclose distress and seek help. In their daily practice they should and can discern normal sorrow from major depression, doubt from obsessive rumination, idiosyncrasy from schizophrenia, and transient responses to extreme events from posttraumatic stress disorder. They have nothing to gain from claims that the pervasive and interminable personal disaster that is posttraumatic stress disorder is not a disorder.

Arieh Y Shalev professor of psychiatry

Department of Psychiatry, Hadassah University Hospital, Jerusalem, 9120 Israel

1 Summerfield D. The invention of post-traumatic stress disorder and the social usefulness of a psychiatric category.

2 Boyle M. Schizophrenia: a scientific delusion. London: Routledge, 1990

3 Pitman RK, Shalev AY, Orr SP. Post-traumatic stress disorder: emotion, conditioning, and memory. In: Gazzaniga MS, ed. The cognitive neurosciences. 2nd ed. Cambridge, MA MIT Press, 2000:1133-48.

4 Shalev AY, Pitman RK, Orr SP, Peri T, Brandes D. Auditory startle in trauma survivors with post-traumatic stres disorder: a prospective study. Am $J$ Psychiatr 2000;157:255-61.

\section{Doctors should relieve suffering, not} debate its existence

Edito - In his views on the sociological origins and implications of post-traumatic stress disorder Summerfield seems to over- look the clinical basis for this complaint. There are real patients who complain of symptoms best described by the diagnostic criteria of the Diagnostic and Statistical Manual of Mental Disorders, fourth edition, and that is why these are used. There is a gradation of traumatic experience, from minor road traffic accident to horrendous atrocity, just as there is a gradation from sadness to full blown depression. That does not make either less of a clinical entity. Dismissing the suffering of a patient with posttraumatic stress disorder as a sociological problem seems like telling a depressed patient to pull himself or herself together.

Summerfield quotes the American Journal of Psychiatry when saying that if anyone liked a psychiatric diagnosis they were given it would be post-traumatic stress disorder. Has he ever really listened to a patient describe the hell of his or her nightmares and flashbacks? Has he looked at his or her pallor, red rimmed eyes, bitten fingernails and thought that this was merely a construct of media hype and compensation neurosis? Perhaps he has been lucky enough never to have an accident or witness any horror in his medical training that had the power to linger in the memory and reappear in dreams? A diagnosis lacking specificity is hardly unique in medicine. Arthritis is a condition with an enormous range of symptoms and severity, but the label itself is not without use both to doctors and patients.

Summerfield also comments on the dependence of post-traumatic stress disorder on external events to define its onset and the recency of this idea as pathological in the context of the long history of man's traumatic memories. Most orthopaedic diagnoses are entirely dependent on external traumatic events for their causation, but we do not find surgeons agonising over whether to nail broken pieces of bone back together just because once they were left to heal as best they could.

Summerfield cites a recent survey in Freetown, Sierra Leone. He comments that the finding of a $99 \%$ incidence of posttraumatic stress disorder is clinically meaningless, presumably simply because the incidence is so high. But is it not possible the incidence is high because terrible events have occurred and the people are suffering? It may be possible to define war as a sociological construct, but its effects on human beings are as real as the people who experience them. It is up to doctors to try to relieve this suffering, not debate its existence.

Juliet Cohen general practitioner Donnington Health Centre, 1 Henley Avenue, Oxford OX4 4DH 
1 Summerfield D. The invention of post-traumatic stress disorder and the social usefulness of a psychiatric category. BMJ 2001;322:95-8. (13 January.)

\section{Logic is flawed}

EDITOR-Summerfield in his article on posttraumatic stress disorder starts with flawed logic and ends in denial. ${ }^{1}$ By starting from an assumption that a psychiatric diagnosis has an objective existence independent of the observer he sets psychiatry in a world of its own. All other diagnoses are observer dependent. All reality is observer dependent. Migraine exists as an illness and may be related to changes of serotonin. It is irrelevant whether neolithic people suffered with what we would call migraine. The concept of migraine is useful in clinical practice. Its existence is dependent on its utility. Homosexuality was once considered a disease. In today's society such a view is laughable. The concept of homosexuality as a disease has lost its utility and so no longer exists.

Summerfield believes that post-traumatic stress disorder is a recent social construct, despite citing evidence that something similar (shell shock) was recognised during the first world war. He doubts that neolithic people had post-traumatic stress disorder and therefore denies its existence. I doubt that neolithic people had much in the way of squamous cell lung cancer, but I do not doubt the utility of such a diagnosis today.

Summerfield thinks that the idea of a traumatic memory being a pathological entity is a recent construct. This concept goes back at least as far as Freud. ${ }^{2}$ It seems not unreasonable that memories of bad events might produce psychological harm. To believe otherwise would mean having to reject the notion that sexual abuse in childhood can result in psychological damage and social dysfunction in adulthood. If you believe in relativity, then, although there may be societal norms of what constitutes a traumatic event, the crucial issue is how an event was perceived by the individual.

Summerfield believes that post-traumatic stress disorder confabulates normality and pathology and devalues "true" illness. The criteria for post-traumatic stress disorder given in the Diagnostic and Statistical Manual of Mental Disorders, fourth edition, specify that the disturbance causes clinically significant distress and impairment in social, occupational, and other important areas of functioning. This is not a description of normality.

Summerfield contributes to the myth that there is an army of professionals supporting unjust claims for damages. The reality is that litigation for personal injury is difficult, slow, and the financial compensation is generally much less than the financial loss. I am yet to meet a claimant who would rather have the money they finally receive than the injury they sustained. He criticises "sympathetic" psychiatrists for assisting claimants. Far better some sympathetic psychiatrists assisting the courts in determining as accurately as possible the true disabilities of claimants than unsympathetic psychiatrists deny suffering and disability on the grounds that they do not think Neanderthal man had similar problems. If a school of psychiatry wishes to distance itself from such patients so be it, but other caring professionals will not.

Simon J Ellis consultant neurologist North Staffordshire Royal Infirmary, Keele University, Stoke-on-Trent, Staffordshire ST4 7LN

1 Summerfield D. The invention of post-traumatic stress disorder and the social usefulness of a psychiatric category $B M J$ 2001; 322: 95-8. (13 January.)

2 Breuer J, Freud S. Studies on hysteria. New York: Basic Books, 2000. (Originally published 1895 .)

3 American Psychiatric Association. Diagnostic and statistical manual of mental disorders DSM-IV-TR (text revision). 4th ed. Washington, DC: APA, 2000.

\section{Social usefulness of any diagnosis needs} consideration

EdiToR-I do not believe that Summerfield's argument is dangerous. ${ }^{1}$ He is simply applying the social constructionist model to posttraumatic stress disorder and this ideology is no more threatening or destructive than the biomedical model.

The social construction of illness and disease is well recognised in the literature on medical sociology, and Summerfield's article adds to an existing debate. The socially constructed nature of (almost?) all illness or disease or disorder is well recognised among medical sociologists and psychologists. Illness and disease cannot exist or emerge separate from society. What is perhaps downplayed in the article and seems to have aroused much angst among respondents is a recognition of the importance of diagnosisany diagnosis-for patients who have a collection of symptoms.

The sociologist Talcott Parsons first recognised the importance of going to the doctor and being diagnosed in his description of the sick role. Regardless of the sociopolitical and medical contexts from which illness or diseases or disorders emerge (although fascinating), in Western society when people's conditions are diagnosed by clinicians the people are generally no longer regarded as personally responsible for causing their illness behaviour. Arguably this removes them from being regarded as deviants or at least morally questionable people and places them firmly into the legitimating hands of medicine. For those with posttraumatic stress disorder, a diagnosis can provide them with much needed legitimacy, allowing them to retain their place within society without diminishing what they are experiencing. It may well be the medicalisation of everyday life, but as long as the biomedical approach dominates the way Western society approaches their problems, it is a very necessary evil. Perhaps we need to start thinking beyond clinical outcomes and start thinking what the real role of medicine is in Western society.

Andrea Litva lecturer in medical sociology Department of Primary Care, Whelan Building University Of Liverpool, Liverpool L69 3GB litva@liverpool.ac.uk

1 Summerfield D. The invention of post-traumatic stress disorder and the social usefulness of a psychiatric category. $B M J$ 9001; $322: 95-8 \cdot(13 \mathrm{~J}$
Accountable methods of validation are needed

EDITOR-Summerfield's article is an example of good intention, poor method, and bad outcome. ${ }^{1}$ Post-traumatic stress disorder is not solely a legacy of the American war in Vietnam. For example, see Herodotus' Aristodemus ("the trembler") in The Histories, or Lady Percy's speech in Shakespeare's Henry $I V$, Part 1 (scene 3).

The kernel of truth to this section of Summerfield's argument is, however, that the Vietnam war led to a ready number of returned servicemen displaying and reporting similar problems. Because of the similarity of symptoms shared with victims of sexual assault, however, this was not called war neurosis

Research requires criteria that ensure comparison of similar presentations. This description (post-traumatic stress disorder), which we shall call a diagnosis, helps make research studies comparable across settings. Debriefing people after a disaster-a process of iatrogenically presenting, priming, and prepping medicalised information-now seems to be a very poor response. ${ }^{2}$ Summerfield warned of this as far back as 1995.

However, people presenting with a cluster of signs (symptoms?) and describing this with a term does not equate to the medicalisation of a problem. Negating it can be a disenfranchisement of the patient. If this is a socially constructed phenomenon, why do we get similar presentation rates, symptoms, and success rates after treatment around the world? When we do not arrive at similar treatment success rates this alerts us to a possible problem with either the sample or the intervention. ${ }^{4}$

Summerfield also seems to be suggesting an argument against the current form of trauma tourism being practised by so many debriefing companies and humanitarian assistance programmes. This is laudable, but different to suggesting that all diagnoses are a Western concept and therefore harmful.

Inhabitants of war torn Sierra Leone are not an example of people with post-traumatic stress disorder. The trauma is current, and the symptoms are, therefore, adaptive. Delineating between true cases and malingering is again an issue of which all therapists and forensic assessors are aware. Yet to dismiss all cases of post-traumatic stress disorder, as Summerfield suggests, as examples of people with a flaccid upper lip is risible. The need for accountable methods of validation is, however, well taken. I question whether Summerfield believes the presented argument himself, but rather is playing Devil's advocate for the sake of debate.

Grant J Devilly senior lecturer

Department of Criminology, University of Melbourne, Parkville, Victoria 3010, Australia. dev@crim.unimelb.edu.au

I Summerfield D. The invention of post-traumatic stress disorder and the social usefulness of a psychiatric category. $B M J$ 2001;322:95-8. (13 January)

2 Kenardy J. The current status of psychological debriefing It may do more harm than good. BMJ 2000;321:1032-3.

3 Summerfield, D. Debriefing after psychological trauma

Inappropriat, D. Debriefing after psychological traum additional harm. $B M J$ 1995;19:509. 
4 Devilly GJ, Foa EB. The investigation of exposure and cognitive therapy: comments on Tarrier et al (1999).J Consul Clin Psychol (in press).

\section{Baby should not be thrown out with bath water}

EDITOR-Summerfield discussed the validity of the diagnosis of post-traumatic stress disorder. ${ }^{1}$ He overstated his case, however, and diluted the impact of his argument by confusing two fundamentally distinct issues. The concept of illness and the validity of medical diagnoses do not necessarily impinge on a consideration of the potential misuse of such diagnoses. Post-traumatic stress disorder is overdiagnosed, having expanded beyond the medical sphere, to those of psychologists, nurses, other health professionals, lawyers, and the media. In modern society, the influence of prevailing individualistic and self centred values and the need for a universal term for suffering that may justify the actions of "victims," litigants, and their advocates may well have contributed to this overexpansion of the concept.

This does not, however, invalidate a diagnosis when used appropriately. AIDS is an obvious example (of many) that denies Summerfield's assertion that an illness must have existed in neolithic times for it to be real. The influence of sociopolitical factors in the genesis of psychological symptoms that may form a diagnostic category similarly does not deny the diagnosis. Psychological, social, and other extrinsic factors are of importance in the pathogenesis of all illnesses, physical as well as psychiatric. Such factors may give rise to illness just as legitimately as genetic aberrations, infection, diet, and lifestyle. Consequently illnesses may indeed come and go through time and across cultures. Summerfield's questions, "Where were they before?" and, "Where did they go?" remain valid, but they do not imply a lack of objective reality.

The reliance of psychiatry on a syndromal classification of disease introduces subjectivity to diagnosis and a vulnerability to misuse and misunderstanding. This is not a problem unique to psychiatry. The problems described by Summerfield may also operate with regard to diagnoses of whiplash injuries after road traffic accidents, post-concussional syndrome, back injuries, chronic fatigue syndrome, and many others. It is not a coincidence that such complaints are commonly the subject of petition and litigation.

The baby (post-traumatic stress disorder) should not be thrown out with the bath water (spurious eponymous diagnoses). Rather, psychiatry should strive to classify psychological reactions to stress more accurately, pursue the holy grail of biological markers to inform and aid appropriate and objective diagnosis, and embrace the task of educating the public and the media in the correct significance and interpretation of current diagnostic labels.

Tom Clark clinical research fellow in psychiatry University of Birmingham, Birmingham B15 2TT

1 Summerfield D. The invention of post-traumatic stress disorder and the social usefulness of a psychiatric category. BMJ 2001:322:95-8. (13 January.)
Questions about current status of psychiatric classification systems arise

EDITOR-Summerfield's paper on posttraumatic stress disorder was long overdue. As a psychiatrist working in Canada and having been trained in Great Britain, I have been overwhelmed by the arbitrariness and the superficiality of the construct "posttraumatic stress disorder," which I encounter almost everyday tagged to some of my patients in an irresponsible fashion.

It is from two Canadian scholars, a philosopher and a historian of psychiatry, that we can get some further insight into Summerfield's incisive critique of this condition. The philosopher, Ian Hacking, in a recent book borrows from another philosopher, John Searle, two concepts that can be applied to Summerfield's analysis. ${ }^{2}$ In discussing the social construction of mental illness, Hacking mentions the fact that young women with anorexia nervosa die from their condition. In this sense their condition is epistemologically objective but ontologically subjective. Post-traumatic stress disorder is also epistemologically objective-people suffer-but it displays ontological subjectivity-it is the result of an elaborate historical process mired in the intricate tapestry of the construction of the Diagnostic and Statistical Manual of Mental Disorders, Third Edition, Revised, and its sequels.

The second Canadian scholar is Edward Shorter, who, in his book From Paralysis to Fatigue, impinges upon the subtle and interactive process between doctors, patients, and cultural mores. ${ }^{3}$ Spinal irritation, reflex theory, gynaecological surgery to cure nervous mental illness, and hysterical fits were the result of this ongoing process. According to Shorter, when the doctor's idea of a "legitimate" disease changes, the patient's idea changes as well. When the doctors shifted their paradigm from reflex neurosis emphasising motor hysteria to the central nervous paradigm of sensory symptoms, the patients shifted accordingly.

I believe that Summerfield's paper elevates the tone of the debate around the unwarranted medicalisation of human suffering rather than confusing it. It also poses questions concerning the current status of psychiatric classification systems.

Casimiro Cabrera-Abreu consultant psychiatrist Regina, Saskatchewan, Canada S4P 2E3 casimiro@sk.sympatico.ca

1 Summerfield D. The invention of post-traumatic stress disorder and the social usefulness of a psychiatric category. BMJ 2001; 322: 95-8. (13 January.)

2 Hacking I. The social construction of what? Cambridge, MA Harvard University Press, 1999.

3 Shorter E. From paralysis to fatigue. A history of psychosomatic illness in the modern era. New York: Free Press, 1992.

\section{Diagnostic label is misleading}

EDITOR-I am in agreement with practically everything Summerfield says in his article on post-traumatic stress disorder. ${ }^{1}$ I work with emergency, aid, and development workers returning from overseas and regularly meet the pain and anguish associated with war, disaster, violence, and suffering.
I would like to see a more rigorous definition of the word trauma. I use it in my mind to mean a piercing of defences and resources, both conscious and unconscious, that is experienced, for a time at least, as overwhelming. It is not applicable to the frustration of missing the bus or the disappointment of failing an exam, for example.

I think of what I call ordinary posttraumatic stress. This is the normal distress and dislocation of shock and suffering, often, in my context, separated from the event itself because the individual has split it off (shelved it if you like) in order to do their job. People sometimes need help with this but the aim is to reconnect them with their own mechanisms, both internal and social, so that they can grieve, learn, and get on with living. I do not regard this as pathological at all. It is wonderful to see people recovering over just two or three appointments.

The psychosocial consequences of traumatic incidents may be difficult for people to come to terms with. It is terrible to "lose" your spouse to brain damage or be unable to work again because of injuries sustained. But this is not post-traumatic stress disorder as I understand it. Post-traumatic stress disorder, to me, is much rarer. I would use it to describe a condition of entrenched collapse of defences and resources over time. Patients from the aid and development world may present one year, five years, after a traumatic event and describe a monumental struggle to overcome difficulties which are now overcoming them. The traumatic situation or event broke through the psychological defences, liberating underlying, unresolved conflicts and terrors such that the process of grieving and healing cannot take place. In my view the logical outcome of "true" post-traumatic stress disorder, if it runs its course, is death.

I agree with Summerfield that the diagnostic label is misleading. The trauma may have triggered the illness, but it is the patient's relation to the trauma that is at the heart of the matter.

Annie Hargrave UKCP (UK Council for Psychotherapy) registered psychotherapist InterHealth, 157 Waterloo Road, London SE1 8US

1 Summerfield D. The invention of post-traumatic stress disorder and the social usefulness of a psychiatric category. BMI 2001; 322: 95-8. (13 January.)

\section{Author's reply}

EDitor-Shalev, Cohen, and Ellis all pitch "suffering" as a form of psychopathology. This distortion may reflect the advantages that accrue to medically attested outcomes, including legitimated sick roles, as Litva and Devilly remind us. But is their objection also aesthetic: is the medicalisation of life now so natural that accounts of suffering which do not deploy the language of trauma seem to be playing down what people have gone through, and are thus distasteful? Surely it would be objectionable to victims of Hillsborough or Omagh to discover that people acknowledged their experiences by attaching a mental disorder to them. What is 
at issue in my paper is not the "reality" of human distress, but the fidelity of a particular psychiatric category.

Ellis should re-read my paper. The assumption that a psychiatric category has an existence independent of the observer is not mine. Psychiatric orthodoxy has always assumed that there was a set of eternal facts (the "baby") to be teased out from their context (the "bath water"). Diseases are discovered, having always existed. Devilly provides an example when he sees posttraumatic stress disorder in the works of Herodotus and Shakespeare. A Vietnam war veteran in the United States has just published a book averring that Alexander the Great had post-traumatic stress disorder. ${ }^{1}$ Perhaps the most radical demonstration of the medicalisation of the past to serve the purposes of the present is the transgenerational trauma movement. Trauma is seen as an entity transmissible to people still unborn when the events took place. (This was once called Original Sin). This affords the child or grandchild of a Holocaust survivor an extra way of having personal unhappiness explained, and a victim identity legitimated. ${ }^{2}$

Of course other psychiatric categories also have histories: for example, that of "depression" reveals the gradual incorporation of the cultural vocabulary of guilt, energy, fatigue, and stress. ${ }^{3}$ It is interesting that British general practitioners have begun to put "stress," in daily use as a folk idiom, on sick certificates instead of "depression" or "anxiety." But post-traumatic stress disorder deserves sociological attention because it is being attached so sweepingly to experiences that till now have been seen as merely part of life. So where did the epidemic of yesterday's unrecognised, untreated cases go to? Shalev is wrong when he implies that a distinct psychobiology for post-traumatic stress disorder has now been identified. Post-traumatic stress disorder is being globalised. Why, as a professor of psychiatry, does he not concede that Western psychiatry is merely one among many ethnopsychiatries, and that post-traumatic stress disorder is a syndrome bound to Western culture?

Clark is right; a diagnostic category is not necessarily to blame if it is misused. But post-traumatic stress disorder is especially amenable to misuse because so many of its criterial features are non-specific and subjective. My own clinical experience of it was honed on over 800 assessments of refugee survivors of human rights abuses. Criteria for post-traumatic stress disorder cannot distinguish between torture and a bicycle accident, exclude a pre-existing psychiatric disorder, nor the impact of current social stressors. Its conceptual basis in supposedly immutable, pathogenic "traumatic" memory is simplistic: memory is interpretative and therefore malleable. Veterans from the Gulf war were given a standard set of questions about their combat experiences one month, and again at two years, after the war had ended. Informants generally reported significantly more traumatic exposure the second time. ${ }^{4}$ This shift may well be pertinent to the construction of Gulf war syndrome, which still seeks the disease status accorded post-traumatic stress disorder.

As Ellis notes, homosexuality was once classified as a psychiatric disorder, a reminder that social attitudes are liable to be recast as freestanding medicopsychological facts. A wise psychiatry is one with an element of self doubt, acknowledging the limitations of a pathology bound biopsychomedical paradigm, rooted in a mechanistic view of man, in capturing the complexity and ambiguity of human experience. As a category post-traumatic stress disorder can support some weight, and I am saying we should debate how much this is, but it cannot support the tower block that has been erected on it.

Derek Summerfield honorary senior lecturer in psychiatry

St George's Hospital Medical School, London SW17 ORE

1 Tritle L. From Melos to My Lai. New York: Routledge, 200 2 Summerfeld D. The psychological legacy of war and atrocity: the question of long-tem and trangeneratonat trects a the quest for a broad view J Nervous and Disetse 1996;184:375-7.

3 Jadhav S. Cultural origins of Western depression. Int SocPsychiatry 1996;42:269-86.

4 Southwick S, Morgan C, Nicolaou A, Charney D. Consistency of memory for combat-related traumatic events in veterans of Operation Desert Storm. Am J Psychiatry 1997;154:173-7.

\section{How policy informs the evidence}

\section{Comprehensive evidence is needed in} decision making

EDITOR-Davey Smith et al have identified some problems with evidence based decision making in health care. ${ }^{1}$ Nevertheless, when these are set against the deficiencies of much current (non-evidence based) decision making, evidence based decision making still compares favourably.

Administrators, facing complex allocation choices within tight budgets, are inclined to focus on economic notions of efficiency and fair play. The rationale is: "If it's not too expensive and seems to help a disadvantaged group we might be prepared to pay for it." When people are presented with a problem (often the solution is presented first, implying that there must be a problem) they gather whatever information will confirm the merit of the intended intervention as quickly as possible. Inequalities in health are not remedied, nor the health of the population as a whole benefited, by this short term damage control.

Computed tomography is important in examining efficacy (the safety and benefits of treatments used under ideal conditions). But to be of value to policymakers, research should seek to identify evidence supporting effectiveness (whether an intervention is likely to do more good than harm in routine use). The evidence needed for sound policymaking should thus be much more

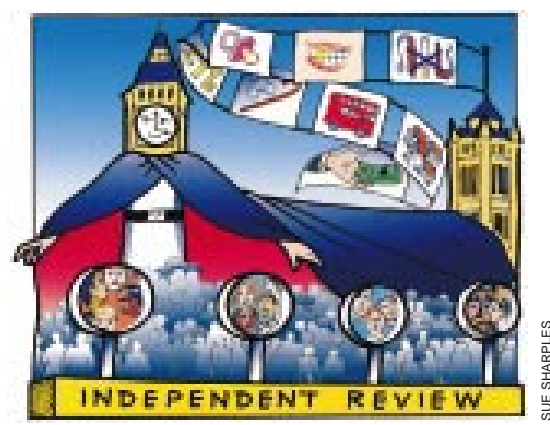

comprehensive than attempts to extrapolate dubious principles from the findings of computed tomography.

Evidence based decision making is, fundamentally, the process of ensuring that the right questions are asked. Is an intervention safe and effective (will it do more good than harm)? Who needs it? Can it be provided under conditions of equal accessibility? Who is the population at risk, and what are the relevant clinical and social determinants? What change may be expected in the burden of disease? What are the social consequences (what are the implications in power and dominance issues, and what public and private interests are being served)? If decisions are based on such comprehensive evidence then the budgetary issues that follow will be much more accurately circumscribed.

Tools exist that can synthesise such data to scientific standards and provide logical and defensible conclusions about impacts on a system, a population, and society. ${ }^{2}$ Decisions can be then be made that are based on meaningful comparison with interventions competing for the same budget.

Ultimately, the aim of decision making in health care should be to achieve not equal health standards (however low the ceiling) but good health for all population groupsor, to put it another way, the best care for the greatest number of people.

Arminée Kazanjian associate director Centre for Health Services and Policy Research, University of British Columbia, Vancouver, British Columbia, Canada V6T 1 Z3

Arminee@chspr.ubc.ca

1 Davey Smith G, Ebrahim S, Frankel S. How policy inform the evidence. BMJ 2001;322:184-5. (27 January.)

2 Kazanjian A, Green CJ, Bassett K, Brunger F. Bone minera density testing in social context. Int J Technol Assess Health Care 1999;15:679-85.

\section{Lessons have also been learnt in disciplines outside medicine}

EDITOR-The case study by Macintyre et al and the lessons that they draw from it are excellent. ${ }^{1}$ These lessons are not unlike experiences and lessons in disciplines outside medicine.

In education, crime, and justice, government groups in the United States and elsewhere have also been formed to identify promising practices, exemplary models, and so forth, on the basis of good evidence. As in the health sector, these organisations have had to confront major challenges in identifying and compiling relevant studies, 
deciding on standards of evidence and when to include or exclude studies, summarising the studies in sensible ways, and deciding that evidence is insufficient for reaching any conclusions and, ultimately, getting the information to the policymaker in a timely fashion.

The Campbell Collaboration (http:// campbell.gse.upenn.edu) was inaugurated in February 2000 for these reasons. Modelled partly on the Cochrane Collaboration in health care, the Campbell Collaboration will prepare, maintain, and make accessible systematic reviews of studies of the effectiveness of interventions in education, crime and justice, social work and social welfare, and other social sectors. The first target is randomised trials; the second target is well controlled non-randomised trials. The ultimate aims are to produce information that is useful to the public and social policymakers and to help stimulate the production of better studies of effectiveness.

Robert F Boruch chair, Campbell Collaboration Graduate School of Education and Statistics Department, Wharton School, 3440 Market Street, University of Pennsylvania, Philadelphia, PA 19104, USA

robertb@gse.upenn.edu

1 Macintyre S, Chalmers I, Horton R, Smith R. Using 2001;322:222-5. (27 January.)

\section{Riluzole for motor neurone disease}

\section{More trials are needed}

EDITOR-We wrote the assessment report of riluzole in motor neurone disease, which was commissioned by the health technology assessment programme for the National Institute for Clinical Excellence (NICE). ${ }^{12}$ We believe that a superficial reading of the advice recently issued by NICE on this subject may not give an adequate understanding of the evidence base for this treatment. ${ }^{34}$

The evidence in favour of riluzole for use in the amyotrophic lateral sclerosis form of motor neurone disease is very weak. The pooled effect estimates for survival outcomes are not conventionally significant, but of greater concern is the disagreement between the trials about the direction and the size of the treatment effect; this apparent heterogeneity remains unexplained.

A European public assessment report from the European Agency for the Evaluation of Medicinal Products also expressed concern about the use of riluzole, in view of the limited evidence of an effect on survival without evidence of a slowing in the rate of deterioration of functional status. ${ }^{5}$ The opinion concludes that there are therefore remaining uncertainties on the product in the management of amyotrophic lateral sclerosis. No further trial data have become available since this time. In the interests of patients we make the following plea to the clinical community.
Ensure that consent to treatment is fully informed and that patients know of the uncertainty about any survival benefit, the modest size of any benefit that might exist, the lack of evidence that functional deterioration is slowed, the toxicity associated with treatment, and the nature of the additional monitoring required for the treatment rather than the disease.

Approach an experienced organisation in the public sector with regard to designing a large randomised trial. Ideally this should include placebo, newer agents, or new combinations if appropriate, and investigate the lower dose of riluzole $25 \mathrm{mg}$ twice daily. One trial compared different doses and reported a dose response effect, but this claim is in error; there is no evidence that $25 \mathrm{mg}$ twice daily is any less effective than $50 \mathrm{mg}$ twice daily, and it may have a more favourable toxicity profile.

Resist the temptation to use this agent outside the licensed indication. There is pressure to use riluzole for motor neurone diseases other than amyotrophic lateral sclerosis, despite an incomplete understanding of the pathophysiology of these diseases (including amyotrophic lateral sclerosis) or the mechanism of action of riluzole, and a complete absence of any trial data in such patients.

Consider the need for trials in other forms of motor neurone disease.

Josie Sandercock research fellow

Amanda Burls senior clinical lecturer

Chris Hyde senior clinical lecturer

Anne Fry-Smith information scientist

Pelham Barton lecturer

Stirling Bryan senior lecturer

Health Services Management Centre, University of Birmingham

Antony Stewart senior lecturer

School of Health Sciences, University of

Wolverhampton, Wolverhampton WV1 1SB

1 Stewart A, Sandercock J, Bryan S, Hyde C, Barton PM, FrySmith A, et al. The clinical effectiveness and costete press).

2 Riluzole for motor neurone disease-HTA report part 1 www.nice.org.uk/pdf/Riluzole htarep_partl.pdf; accessed www.nice.org.

3 National Institute for Clinical Excellence. Guidance on the use of riluzole (Rilutek) for the treatment of moto neurone disease. www.nice.org.uk/pdf/RILUZOLE_fulguidance.pdf; accessed $5 \mathrm{Feb} 2001$. (Technology appraisal guidance No 20 .

Kmietowicz Z. NICE approves drugs for Alzheimer's disease. BMJ 2001;322:190. (27 January.)

5 Committee for Proprietary Medicinal Products. Europea public assessment report (EPAR). Rilutek. London: Europea Agency for the Evaluation of Medicinal Products, 1999.

\section{Large, more economical trial is needed}

EDITOR-We are surprised that the National Institute for Clinical Excellence (NICE) has recommended that riluzole be made available in the NHS to patients with motor neurone disease. ${ }^{1}$ The only statistic presented in the guidance document, and therefore presumably the primary evidence on the basis of which this decision was made, is a hazard ratio of 0.88 with a $95 \%$ confidence interval of 0.75 to 1.02 for tracheostomy free survival (this is incorrectly reported as a $17 \%$ relative reduction). ${ }^{2}$ The upper confidence limit is greater than 1.0, meaning that there is not a conventionally significant benefit at the 0.05 level or, to put it another way, the result is statistically compatible with there being no benefit at all for riluzole. No supporting evidence on other factors, such as quality of life, was presented to add weight to the trend towards better survival.

NICE seems to be recommending a treatment when there is no significant evidence of benefit. Of course, $\mathrm{P}=0.05$ should not be regarded as a "magic number," so a result of borderline significance, say $\mathrm{P}=0.04$, would also not have been sufficient to prove the case for riluzole since the upper confidence limit would still have been consistent with too small a benefit to justify treatment.

Furthermore, the NICE recommendation is contrary to the conclusion of the expert group at the West Midlands Development and Evaluation Service, commissioned by the NHS on NICE's behalf to review the evidence on riluzole. This group, to which one of us (KW) was an adviser, concluded that considerable uncertainty remains about the true benefit of riluzole, if any. ${ }^{34}$

Riluzole may be an effective and worthwhile treatment for motor neurone disease; on the other hand, it may not-we do not know at the current time. Instead of spending up to $£ 7.5 \mathrm{~m}$ per year, recurrently, on a treatment that may or may not work, the NHS would be better advised to invest in a further large trial that would cost considerably less. This, when taken in conjunction with the data already available, would provide much more definitive evidence to guide the future use of riluzole in motor neurone disease. Unfortunately, NICE's pronouncement is likely to make such a trial very difficult, if not impossible, to undertake in the United Kingdom.

The supposed aim of NICE is to increase the practice of evidence based medicine, but this decision is likely to achieve the opposite effect.

Keith Wheatley deputy director

k.wheatley@bham.ac.uk

Richard Gray director

University of Birmingham Clinical Trials Unit, Birmingham B15 2RR

1 Kmietowicz Z. NICE approves drugs for Alzheimer's disease. BMJ 2001;322:190. (27 January)

2 National Institute for Clinical Excellence. Guidance on the use of riluzole (Rilutek) for the treatment of motor neurone disease wwwnice orguk/pdf/RILUZOLE full puidancepdf; accessed 5 Feb 2001. (Technology apprai

3 Stewart A, Sandercock J, Bryan S, Hyde C, Barton PM, FrySmith A, et al. The clinical effectiveness and costeffectiveness of riluzole for motor neurone disease: a rapid and systematic review. Health Technology Assessment (in press).

4 Riluzole for motor neurone disease-HTA report part 1. www.nice.org.uk/pdf/Riluzole_htarep_part1.pdf; accessed 5 Feb 2001

\section{Ambiguous diagnostic criteria mean that} wide variations in eligibility may still persist

Editor-If the National Institute for Clinical Excellence (NICE) aims to reduce wide variability in the prescribing of drugs for the treatment of dementia, it has reckoned without highly subjective diagnostic criteria. ${ }^{1}$ In particular, uncertainty surrounding the interface between vascular dementia and 
Alzheimer's disease is no longer a diagnostic nicety for researchers but will determine treatment eligibility for large numbers of people with dementia.

The most commonly used research criteria for Alzheimer's disease state that it can only be diagnosed if no other primary cause-for example, cerebrovascular disease - has been identified. ${ }^{2}$ At what level of cerebrovascular disease therefore does a clinician decide whether criteria for Alzheimer's disease are fulfilled? Is this appropriate if, as pathological evidence suggests, infarction may frequently initiate dementia in the presence of Alzheimer's disease? ? $^{3}$ Does comorbid stroke rule out a diagnosis of Alzheimer's disease, and therefore treatment with anticholinesterase? If it is treated as an exclusion criterion then many patients with Alzheimer's disease may fail to receive treatment because of comorbid disease. This will include minority groups such as African Caribbean elders, who have a raised risk of cerebrovascular disease. ${ }^{4}$ An ominous possibility is that such decisions will be left up to the varying opinion of prescribing specialists. Isn't this what NICE is there to prevent?

Robert Stewart Wellcome Trust research training fellow in clinical epidemiology

Section of Old Age Psychiatry, Institute of

Psychiatry, London SE5 8AF

r.stewart@iop.kcl.ac.uk

1 Kmietowicz Z. NICE approves drugs for Alzheimer's disease. BMJ 2001;322:190. (27 January.)

2 McKhann G, Drachman D, Folstein M, Katzman R, Price D, Stadlan EM. Clinical diagnosis of Alzheimer's disease. Report of the NINCDS-ADRDA Work group under the erport of . Services Task
1984:34:939-44.

3 Snowdon DA, Greiner LH, Mortimer JA, Riley KP, Greiner

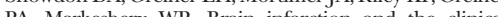
A, Markesbery WR. Brain infarction and the clinica ease. JAMA 1997;277:813-7.

4 Stewart JA, Dundas R, Howard RS, Rudd AG, Wolfe CDA Ethnic differences in incidence of stroke: prospective study with stroke register. BMJ 1999;318:967-71.

\section{French cardiovascular mortality did not increase during 1996 European football championship}

EDItor-Witte et al found a significant increase in mortality from coronary heart disease and stroke in Dutch men aged $\geqslant 45$ on the day that the Dutch team was eliminated by the French from the 1996 European football championship compared with the five days before and after the match (relative risk 1.51; 95\% confidence interval 1.08 to 2.09$){ }^{1}$ We reassessed this hypothesis using corresponding French data.
The match had an audience of 4.7 million television viewers in France (around $8 \%$ of the French population). We performed the same time series analysis as Witte et al on French mortality data for the periods and personal characteristics corresponding to the Dutch data, the cause of death being classified according to ICD-9 (international classification of diseases, ninth revision, codes 410; 430-434; 436-438).

The table shows that, on the day of the match, mortality from all causes did not increase among French men or women compared with that on the five days before and after the match. In particular, mortality from myocardial infarction or stroke did not increase. On the day of the match 61 deaths from myocardial infarction or stroke were reported; on the day after the match 104 such deaths were reported.

The Dutch results were not confirmed by the French data, and we therefore question Witte et al's conclusion; they might have reached another conclusion had they used larger time windows. Furthermore, how many of the 41 people reported dead from myocardial infarction or stroke actually watched the match?

During and after the World Football Cup held in France from June 10 to July 12 1998 we set up electronic sentinel disease surveillance to estimate the incidence of various conditions in the French population. The incidence of the conditions we looked at might be affected by increased stress, possibly caused by an important football match.

Analysis of our data showed no relevant variation in the disorders surveyed. At the population level the effects of stress induced by important sporting events on health are probably minor. ${ }^{2}$ The level of population exposure to the risk factor (watching the match on television) was not the same in the French and Dutch populations (8\% v 60\%); this may have affected people's behaviour as regards alcohol consumption, smoking, and collective excitement. In addition, the match resulted in a nil-nil draw, and France won on penalty kicks. The result of a match may also have its effects.

Further studies are needed to establish whether the findings in the Dutch population are the result of chance or whether this is another French paradox.

L Toubiana researcher

toubiana@u444.jussieu.fr

T Hanslik doctor in internal medicine

L Letrilliart medical epidemiologist

INSERM Unit 444, Saint-Antoine Medicine Faculty, Paris VI University, Paris, France
All cause mortality and mortality from myocardial infarction or stroke on day of match compared with the five days before and after the match, men and women, France

\begin{tabular}{lll} 
& No of cases & Relative risk (95\% Cl) \\
\hline All cause mortality: & & \\
\hline Men & $601.0 \vee 640.6$ & $0.94(0.88$ to 1.00$)$ \\
\hline Women & 566.0 v 606.2 & $0.93(0.82$ to 1.08$)$ \\
\hline Mortality from myocardial infarction and stroke: & & \\
\hline Men & $61.0 \vee 82.8$ & $0.74(0.58$ to 1.02$)$ \\
\hline Women & $83.0 \vee 86.6$ & $0.96(0.80$ to 1.21$)$ \\
\hline
\end{tabular}

We thank Médiamat-Médiametrie for providing the total audience of French television viewers and the Service Commun No 8, INSERM, for providing the mortality data.

1 Witte DR, Bots ML, Hoes AW, Grobbee DE. Cardiovascular mortality in Dutch men during 1996 European football championship: longitudinal population study. BMJ championship: longitudinal pop

Hanslik T, Espinoza P, Boelle PY, Cantin-Bertaux D, Gallichon B, Quendez S, et al. Sentinel monitoring of general community health during the 1998 world football cup. Re Epidemiol Sante Publique (in press).

3 Renaud S, de Lorgeril M. Wine, alcohol, platelets, and the French paradox for coronary heart disease. Lancet 1992;339:1523-6.

\section{Athlete's foot and fungally infected toenails}

\section{Authors should use familiar drug names}

EDITOR-The review of effectiveness of treatments for athlete's foot seemed perfectly timed ${ }^{1}$ : my shopping list for that Saturday morning included a fungicide to control the infection under my toes. I read it eagerly but ended up none the wiser because the names used for the drug groups were unfamiliar to me. I consulted my copy of the British National Formulary, ${ }^{2}$ confident that the mystery would be solved. No luck: the terminology in the review wasn't used there.

OK, I thought, I'll ask the pharmacist. But when he looked at the term I'd carefully copied from my $B M J$ his first assumption was that I'd got it wrong, because he had never heard of it either. Nor did any of his reference books mention it

The way that the authors classified the products that they discussed made the review far less useful than it could have been. What was needed was a simple table listing which products were included in each group (allylamines and azoles). I am surprised that the editors of the $B M J$ did not ask for this.

The underlying problem is common in systematic reviews of research evidence: authors rarely seem to consider the practical application of the information that they gather so meticulously. Evidence based medicine requires effective communication between the reviewers of research and those who would implement it; one crucial aspect of this is choosing terms that are actually used and understood by potential readers.

Arabella Melville freelance consultant and writer Porthmadog, Gwynedd LL49 9AN Arabella_Melville@port35.freeserve.co.uk

1 Crawford F, Hart R, Bell-Syer S, Torgerson D, Young P, Russell I. Extracts from "Clinical Evidence": athlete's foot Russell I. Extracts from "Clinical Evidence": athlete's foot
and fungally infected toenails. BMJ 2001;322:288-9. (3 and fungal

2 BMA, Royal Pharmaceutical Society of Great Britain. British national formulary. London: BMA, RPS, 2000. (No 39.)

\section{Authors' reply}

Editor-Melville's comments about our review in Clinical Evidence highlight an important issue. It was our aim to produce a comprehensive review of the evidence of effectiveness of creams to treat athlete's foot. We are therefore concerned that Melville couldn't find information about one of the drugs in the British National Formulary. 
Although she doesn't name the drug, we deduce that it was ciclopiroxolamine: this is the only drug in the review that is not mentioned in the formulary. ${ }^{1}$ It is not available in the United Kingdom.

It was unfortunate that the pharmacist was unable to help; reference to Martindale. The Complete Drug Reference Guide would have shown that ciclopiroxolamine is sold as 13 different proprietary products in 10 countries worldwide (excluding the United Kingdom). ${ }^{2}$ Tolnaftate is sold as a single ingredient in 30 proprietary preparations in 11 countries and is one ingredient in a further 14 multi-ingredient products. Undecanoic acid is available as Mycil cream in the United Kingdom, but in seven other countries it has 16 different brand names. It can be found in 60 multi-ingredient products in 12 countries. A table of generic names for classes of drugs is a good idea and will be part of the update of the chapter in issue 6 of Clinical Evidence; a table listing brand names is simply impractical.

The review on athlete's foot in Clinical Evidence aims at informing an international audience and a varied medical staff (dermatologists, general practitioners, nurses, pharmacists, and other professionals allied to medicine); all will have different levels of knowledge about antifungal preparations. They will often have access to a drug formulary in which this information is available, but a table of generic names for classes of drugs will certainly be helpful.

Fay Crawford MRC fellow

fc5@york.ac.uk

Sally E M Bell Syer research fellow

David J Torgerson reader

Philip Young biostatistician

Ian Russell professor

Department of Health Sciences and Clinical

Evaluation, University of York, York YO10 5DD

Rachel Hart research podiatrist

Podiatry Department, University of Wales Institute, Cardiff CF1 3NS

Stuart Barton editor

Clinical Evidence, BMJ Publishing Group, London WC1H 9JR

1 BMA, Royal Pharmaceutical Society of Great Britain. British national formulary. London: BMA, RPS, 2000. (No 39.)

2 Parfitt K, ed. Martindale. The complete drug reference guide. 32nd ed. London: Pharmaceutical Press, 1999.

\section{Medical students see that academic misconduct is common}

EDITOR-Rennie and Crosby found that the threshold for cheating is low among medical students. ${ }^{1}$ In an accompanying editorial Glick commented that a "pervasive institutional culture of integrity is essential" to encourage professional conduct and minimise fraud. ${ }^{2}$ Academics should be a role model in terms of good scientific practice, but we are far from this ideal.

In 2000 I introduced into the curriculum a seminar for fifth year medical students. We discussed principles of scientific integrity, according to guidelines of the German research council, ${ }^{3}$ which had just been put together after a high profile case of scientific fraud.

In 2000 I taught this course six times. On each occasion I distributed a 10-item questionnaire. Altogether 229 students completed it (response rate 97\%). Of the 201 who had already done research for their MD dissertation, 12 "completely agreed," on a 5-point Likert scale, with the statement that the climate in their research group was such that "students have to deliver the results that are expected by the supervisor."

International authorship criteria demand that authors should have participated both in planning or conducting the research and in writing or critically revising the manuscript. Of the 51 students who had already been listed as coauthor of a research paper, 18 reported that at least one of these criteria had not been met in their own case and 24 said that at least one had not been met by at least one of the coauthors; 16 reported that the department head had been made an honorary author.

Sixteen students had been omitted as author from a publication despite having contributed work, and nine had been the victim of plagiarism. Five admitted that they had themselves taken words or ideas from other people without credits, five that they had presented results selectively, and seven that they had trimmed or falsified results.

Of the 201 students who had done research, a high proportion reported that they had observed others engaging in unethical practices. These included selective reporting (43\%), trimming or falsifying results $(36 \%)$, wrong or inappropriate authorship attribution (25\%), multiple publication of the same result ("salami publication") (18\%), presentation of results in a wilfully misleading way $(14 \%)$, and plagiarism (14\%).

Certain forms of academic misconduct are still common. We may therefore have difficulties creating "a peer pressure in which certain behaviour simply is not acceptable." Medical students are being educated in an environment where the attitude "everyone does it" (frequently heard as an excuse by researchers engaging in misconduct ${ }^{45}$ ) is being fostered.

Gunther Eysenbach researcher

Department of Clinical Social Medicine, University of Heidelberg, 69115 Heidelberg, Germany ey@yi.com

1 Rennie SC, Crosby JR. Are "tomorrow's doctors" honest? Questionnaire study exploring medical students' attitude and reported behaviour on academic misconduct. $B M$ 2001:322:274-5. (3 February)

2 Glick SM. Cheating at medical school. BMJ 2001:322:250-1. (3 February.)

3 DFG Kommission, Selbstkontrolle in der Wissenschaft.

3 DFG Kommission, Selbstkontrolle in der Wissenschaft
Vorschläge zur Sicherung guter wissenschaftlicher Praxis Vorschläge zur Sicherung guter wissenschaftlicher Praxis
[German Research Council, Commission on Self Control [German Research Council, Commission on Self Control
in Science. Proposals for assurance of good scientific practice.] 1998 (accessed 2 Feb 2001)

4 Dalton R. Professors use web to catch students who plagiarize... and author gets similar paper retracted. Natur 1999;402:222.

5 Eysenbach G. Report of a case of cyberplagiarism-and reflections on detecting and preventing academic misconduct using the internet. J Med Internet Res 2000;2:e4 www.jmir.org/2000/1/e4; accessed 3 May 2001.

\section{Single use disposable equipment is not being used everywhere}

Editor-The Department of Health has announced funding for single use disposable equipment for tonsillectomy operations and lumbar punctures because of the possible risk of transmission of the factor causing new variant Creutzfeld-Jakob disease. ${ }^{1}$ We have audited the use of disposable equipment for diagnostic bone marrow examination.

We surveyed 17 haematology units in the West Midlands, where roughly 125 diagnostic bone marrow aspirations per 100000 population are carried out. Only 12 units were using disposable aspirate and trephine needles for all examinations. The remaining five units were using sterilised reusable needles to some extent; of these, three were using disposable trephine needles but reusable aspirate needles. Some units specified that single use needles would always be used for sampling in children and HIV infection.

The abnormal prion protein has been found in lymphatic tissue and may not be inactivated by normal sterilisation procedures. Bone marrow is part of the lymphoreticular system, and therefore bone marrow aspiration and biopsy may confer a risk of transmission of new variant CreutzfeldJakob disease similar to that conferred by tonsillectomy operations. Single use aspirate and trephine needles are widely available and provide a sample quality that is equivalent to that provided by reusable needles. They would have considerable cost implications, however, for units that have not adopted their use.

The Department of Health has suggested that consideration should be given to using single use instruments. ${ }^{2}$ Because our survey showed a lack of uniformity in current practice, however, perhaps the department should issue further guidance and specific funding. Furthermore, as bone marrow harvests are often undertaken in healthy donors, should this practice be reviewed, and should single use bone marrow harvest needles be made more widely available?

Sandra Young Min specialist registrar sandrayoungmin@yahoo.co.uk

Aamer Aleem specialist registrar

Magda Jabbar Al-Obaidi specialist registrar Elizabeth Justice senior house officer Christopher D Fegan consultant haematologist Department of Haematology, Birmingham

Heartlands Hospital, Birmingham B9 5SS

\section{Charter D. Surgeons will "use and bin" equipment. Times $2001 \mathrm{Jan} 5$. \\ rtment of Health. Variant Creutzfeldt-Jakob disease (vCID): minimising the risk of transmission. London: $\mathrm{DoH}$, 1999. (Health service circular HSC1999/178.)}

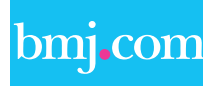

\section{Rapid responses}

Correspondence submitted electronically

is available on our website 